Review Article

\title{
TSC1 and TSC2 gene mutations and their implications for treatment in Tuberous Sclerosis Complex: a review
}

\author{
Clévia Rosset ${ }^{1,2}$, Cristina Brinckmann Oliveira Netto ${ }^{3}$ and Patricia Ashton-Prolla ${ }^{1,2,3,4}$ \\ ${ }^{1}$ Laboratório de Medicina Genômica, Centro de Pesquisa Experimental. Hospital de Clínicas de Porto \\ Alegre (HCPA), Porto Alegre, RS, Brazil. \\ ${ }^{2}$ Programa de Pós-Graduação em Genética e Biologia Molecular, Universidade Federal do Rio Grande do \\ Sul (UFRGS), Porto Alegre, RS, Brazil. \\ ${ }^{3}$ Serviço de Genética Médica, Hospital de Clínicas de Porto Alegre (HCPA), Porto Alegre, RS, Brazil. \\ ${ }^{4}$ Departamento de Genética, Universidade Federal do Rio Grande do Sul (UFRGS), Porto Alegre, RS, \\ Brazil.
}

\begin{abstract}
Tuberous sclerosis complex is an autosomal dominant disorder characterized by skin manifestations and formation of multiple tumors in different organs, mainly in the central nervous system. Tuberous sclerosis is caused by the mutation of one of two tumor suppressor genes, TSC1 or TSC2. Currently, the development of novel techniques and great advances in high-throughput genetic analysis made mutation screening of the TSC1 and TSC2 genes more widely available. Extensive studies of the TSC1 and TSC2 genes in patients with TSC worldwide have revealed a wide spectrum of mutations. Consequently, the discovery of the underlying genetic defects in TSC has furthered our understanding of this complex genetic disorder, and genotype-phenotype correlations are becoming possible, although there are still only a few clearly established correlations. This review focuses on the main symptoms and genetic alterations described in TSC patients from 13 countries in three continents, as well as on genotype-phenotype correlations established to date. The determination of genotype-phenotype correlations may contribute to the establishment of successful personalized treatment for TSC.
\end{abstract}

Keywords: Tuberous sclerosis complex, TSC mutations, genotype-phenotype correlations, TSC1, TSC2.

Received: December 15, 2015; Accepted: March 1, 2016.

\section{Tuberous Sclerosis Complex}

Tuberous sclerosis, also known as Tuberous sclerosis complex (TSC) is an autosomal dominant neurocutaneous and progressive disorder, frequently characterized by the occurrence of multiple tumors in different organs. Penetrance reaches $95 \%$ and is variable; expressivity also varies greatly even within a given family (Northrup et al., 1993). The incidence of TSC is $1 / 10,000$ births, and its prevalence in the general population of Europe has been estimated to be 8.8/100,000 (Orphanet: Tuberous Sclerosis), affecting multiple ethnic groups (Joinson et al., 2003).

\section{Diagnosis and symptomatology}

Tuberous sclerosis has been initially described by von Recklinghausen in 1862. In 1908, Heinrich Vogt established the diagnostic criteria for TSC as the so-called triad:

Send correspondence to Patricia Ashton Prolla. Serviço de Genética Médica, Hospital de Clínicas de Porto Alegre, Rua Ramiro Barcelos 2350. 90035-903 Porto Alegre, RS, Brazil. E-mail: pprolla@ hcpa.edu.br. epilepsy, mental retardation and adenoma sebaceum. As none of these clinical signs were pathognomonic for TSC, clinical diagnostic criteria were revised by a consortium in 1998 (Roach et al., 1998), which proposed three diagnostic categories (definite, probable or possible TSC) based on the presence of major and/or minor features of the disease. Table 1 shows the revised and updated diagnostic criteria for TSC, established by the same consortium in 2012 (Northrup et al., 2013). A definite clinical diagnosis is made when two major features, or one major feature plus two minor features are present. Importantly, most major features are localized to the skin and central nervous system. Also, one must consider that the clinical manifestations of TSC appear at distinct developmental points, and a person with suspected TSC may need multiple sequential evaluations before a definite clinical diagnosis can be made.

After skin and CNS findings, renal manifestations are the most common abnormalities associated with TSC. These include renal cell carcinoma, oncocytomas, angiomyolipomas (in $80 \%$ of patients) and renal cystic disease 
Table 1 - Revised Diagnostic Criteria for Tuberous Sclerosis Complex *.

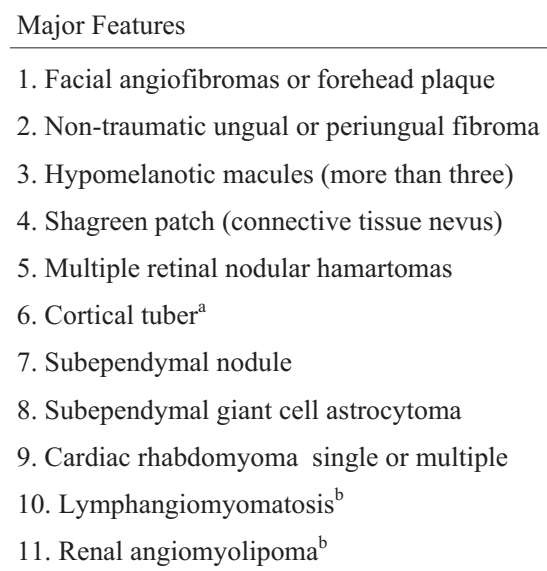

Definite TSC: Either 2 major features or 1 major feature with 2 minor features

Probable TSC: One major feature and one minor feature

Possible TSC: Either 1 major feature or 2 or more minor features

\footnotetext{
${ }^{*}$ Revised Diagnostic Criteria for Tuberous Sclerosis Complex established by a consortium in 2012 (Northrup et al., 2012).

${ }^{a}$ When cerebral cortical dysplasia and cerebral white matter migration tracts occur together, they should be counted as one rather than two features of TSC.

${ }^{b}$ When both lymphangiomyomatosis and renal angiomyolipomas are present, other features of TSC should be present before a definitive diagnosis is assigned.

${ }^{\mathrm{c}}$ Histologic confirmation is suggested.

${ }^{\mathrm{d}}$ Radiographic confirmation is sufficient.

${ }^{\mathrm{e}}$ One panel member recommended three or more radial migration lines constitute a major feature.
}

(in 50\% of the patients) (Dixon et al., 2011). Typically, renal manifestations in children with TSC are first seen in infancy and increase with age. Angiomyolipomas, one of the leading causes of death in TSC patients, are multiple and often bilateral. The associated mortality is due to complications when these lesions become very large. Another consequence of angiomyolipomas is destruction of the normal renal parenchyma, resulting in renal failure and end-stage renal disease (Shepherd et al., 1991). Patients with clinically detectable renal cystic disease usually have a severe very early-onset polycystic phenotype (about $2 \%$ of TSC patients) (Sampson et al., 1997).
Pulmonary involvement, specifically lymphangioleiomyomatosis (LAM), is the third most common cause of TSC-associated morbidity, occurring in approximately $35 \%$ of female TSC patients. LAM is caused by proliferation of atypical smooth muscle cells in the peribronchial, perivascular, and perilymphatic tissues of the lung (Kumasaka et al., 2004). LAM occurs almost exclusively in young women, typically presenting between 30 to 35 years of age. Symptoms have been reported to begin or worsen during pregnancy, suggesting that LAM may be hormonally influenced (Castro et al., 1995).

Skin lesions are detected in $70 \%$ of patients with TSC and include hypomelanotic macules, shagreen patches, confetti-like lesions, forehead fibrous plaque, facial angiofibromas, and periungual and ungual fibromas (Schwartz et al., 2007). Depending on studied population, even as many as $100 \%$ of TSC patients younger than five years may present with hypopigmented macules. An aggregation of reddish papules, appearing on the nose and cheeks in a characteristic butterfly distribution, belongs to the Vogt triad of signs. Although usually symmetrical, occasionally they may be found unilaterally (Jozwiak et al., 1998). Facial angiofibromas (adenoma sebaceum) are formed by hamartomatous growth of dermal connective tissue with rich vasculature and can result in decreased quality of life since they affect appearance, may cause disfigurement, and are prone to bleeding, which increases the possibility of infection (Yates, 2006). Shagreen Patches are areas of thick, irregularly shaped, and elevated skin, usually found on the lower back. Mean age of appearance is about 8.1 years (Sun et al., 2005). Ungual and subungual fibromas are small tumors that grow around and under toenails or fingernails. Their mean age of appearance is 14.9 years (Sun et al., 2005 ) and their prevalence in older patients (above 30 years) is close to $90 \%$. Forehead plaques appear under the age of 14 years (Jozwiak et al., 1998), with mean age of appearance being 2.6 years (Sun et al., 2005).

TSC is also associated with both retinal and nonretinal ocular findings (Rowley et al., 2001). Hamartomas are the most common retinal manifestation of TSC and are identified in approximately 40 to $50 \%$ of individuals. Fortunately, they rarely compromise vision, although severe decreases in visual acuity and blindness has been reported in some cases due to hamartoma enlargement, macular involvement, retinal detachment, and vitreous hemorrhage (Robertson, 1999).

Multiple cardiac rhabdomyomas are cardiac tumors most frequently encountered during infancy and childhood and they occur in approximately $30 \%$ of TSC patients. On the other side, nearly $100 \%$ of fetuses with multiple rhabdomyomas have TSC. Cardiac rhabdomyomas usually do not cause symptoms or hemodynamic compromise, and the natural history for these lesions is spontaneous regression in the vast majority of cases. However, a minority of the cases may become symptomatic shortly after birth or in the 
first year of life. Finally, hamartomas may also occur in organs of the endocrine system and rare case reports exist of angiomyolipomas or fibroadenomas in the pituitary gland, pancreas, or gonads (O'Callaghan and Osborne, 2010).

\section{Neurological involvement}

Neurologic complications are the most common and often the most impairing aspect of TSC. Structural neurological abnormalities include cortical tubers, subependymal nodules (SENs) and subependymal giant cell tumors (SGCTs). Brain tumors in TSC are rare (2 to $10 \%$ of patients with TSC and 1.1-1.4\% of all pediatric brain tumors) (Frèrebeau et al., 1985). Cortical tubers are developmental abnormalities present in more than $88 \%$ of children with TSC (Cuccia et al., 2003), and the average number of tubers per patient ranges from 5 to 50 in different studies. Tubers lead to loss of the classical six-layered cyto-architecture of the cerebral cortex and are thought to be responsible for more than $75 \%$ of the epileptic disorders in patients with TSC (Orphanet: Tuberous Sclerosis). The second more frequent structural neurological lesions in children with TSC are SENs, which are small hamartomas that occur in the walls of the lateral ventricles. Only SENs located in the region of the Monro foramina may have the potentiality to grow and to transform into SGCTs (5\%-20\% of patients). The last but not least important type of encephalic lesion is SGCT, affecting an average of $10 \%$ of children with TSC. SGCTs are benign, slow-growing tumors of mixed glioneuronal cells including giant cells. They are typically located near the foramen of Monro, hence they can cause increased intracranial pressure, obstructive hydrocephalus, focal neurologic deficits and death (Orphanet: Tuberous Sclerosis, 2015). Approximately $90 \%$ of TSC patients experience seizures and about $50 \%$ have documented cognitive impairment, autism, or other behavioral disorders.

Epilepsy is likely the most prevalent and challenging clinical manifestation of TSC, and virtually all subtypes of seizure have been reported. At least one third of patients develop refractory epilepsy; attention deficit-hyperactivity disorder and psychiatric comorbidities, such as mood disorders, anxiety, obsessive compulsive behavior and alcoholism are also frequently present. Among the different sites of tumor development, the brain remains undoubtedly the most problematic in terms of therapeutic management and screening. Brain tumors are the cause of more than $50 \%$ of deaths among children with TSC (Webb et al., 1996). Intellectual disability has a prevalence of $40 \%-50 \%$ in TSC; $30 \%$ are severely affected with IQs in the very low range, and $70 \%$ have IQs in the normal, yet slightly left-shifted range (Joinson et al., 2003).

\section{Molecular genetics of TSC: the TSC1 and TSC2 genes}

Tuberous sclerosis is caused by mutations in one of two tumor suppressor genes: TSC1 (9q34) and TSC2 (16p13.3). The TSC1 gene spans about $53 \mathrm{~kb}$ of genomic DNA with 23 exons coding for hamartin, a hydrophilic protein with 1164 amino acids and $130 \mathrm{kDa}$. Hamartin is expressed in several adult tissues and plays a key role in the regulation of cell adhesion. This protein shows no homology with any other vertebrate protein. The TSC2 gene comprises approximately $43 \mathrm{~kb}$ of genomic DNA with 41 exons encoding a $5.5 \mathrm{~kb}$ transcript and a 1807 amino acid protein, tuberin, with $198 \mathrm{kDa}$. This protein contains a hydrophilic N-terminal domain and a conserved 163 amino acid region encoded by exons 34-38, near the C-terminal portion, which has homology with the Ras superfamily GTPases proteins rap1GAP and mSpal (Maheshwar et al., 1997). Therefore, tuberin is a GTPase activating protein that regulates the GTP binding and hydrolysing activity of the Ras superfamily of proteins and helps to regulate cell growth, proliferation and differentiation. The other domains of tuberin are less conserved, and additional homologies between tuberin and other proteins have not been identified. Serfontein et al. (2011) used bioinformatics tools to examine the presence of conserved elements of TSC1 and TSC2 across different organisms. The analyzed organisms showed a wide range in the degree to which residues implicated in signalling are conserved (or present at all) in comparison to the human TSC1 and TSC2 sequences. Not surprisingly, the mammalian proteins of Rattus norvegicus and Mus musculus shared the largest number of residues with the human proteins.

Figure 1A schematically shows the structure of TSC1 and TSC2 genes, their coding exons and the main domains of hamartin and tuberin. These proteins bind each other via their respective coiled-coil domains to form an intracellular complex that integrates signals to control cellular homeostasis, oxygen levels, presence of nutrients, energy pool, and stimulation by growth factors. Such signals regulate Rheb (a Ras homologue enriched in brain), responsible for the activation of mTOR (mammalian target of rapamycin) kinase. mTOR, in turn, regulates the translation of a significant proportion of cellular proteins, including those responsible for the control of cell growth and proliferation (Kwiatkowski, 2003).

Figure 2 shows the role of the TSC2:TSC1 complex in the mTOR pathway. Loss of function mutations in TSC1 or TSC2 lead to deregulated expression patterns in this pathway, abnormal production of the end products, and ultimately promote tumorigenesis. To date, specific mechanisms by which these loss of function mutations cause disease are not established. It is suggested that tumor formation is initiated as a consequence of at least two hits (Knudson, 1971): as TSC1 and TSC2 are tumor suppressor 
A

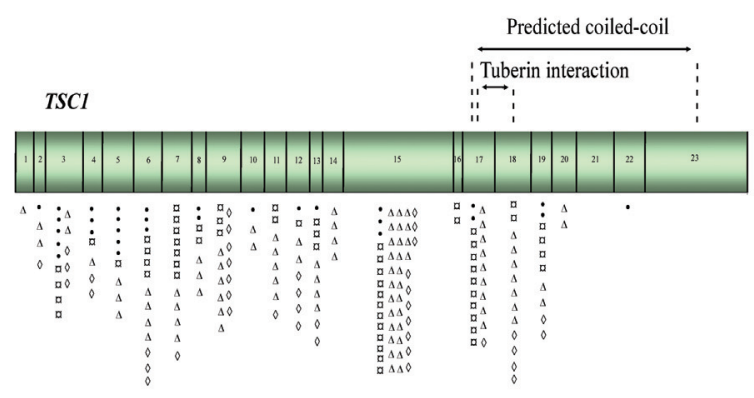

B
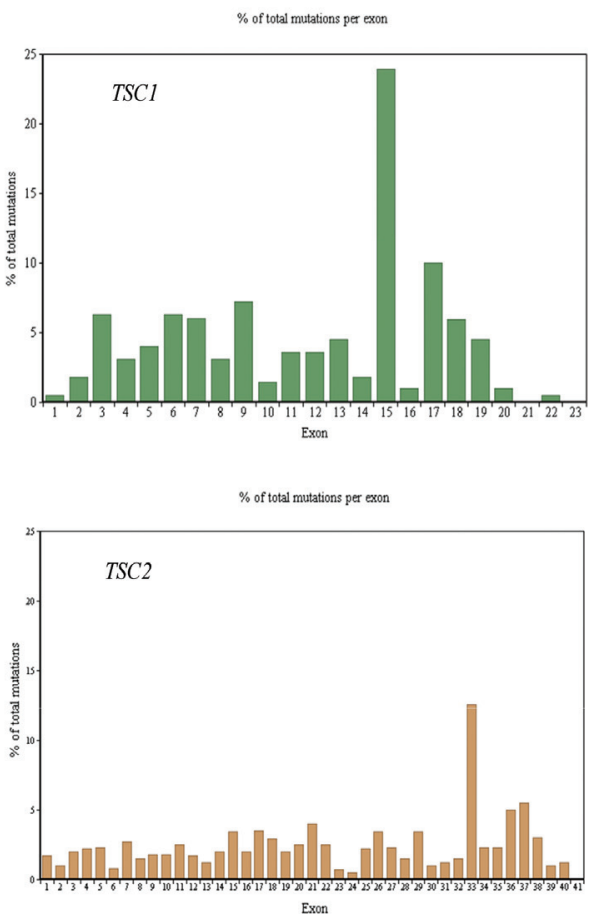

Figure $1-T S C 1$ and TSC2 gene structure, domains and distribution of point mutations. (A) Schematic representation of TSC1 and TSC2 exons and the domains of hamartin and tuberin, respectively, codified by them. The symbols represent the number of different mutations described at each exon. (B) The graph shows the percentage of the total number of described mutations that occur at each TSC1 and TSC2 exon.

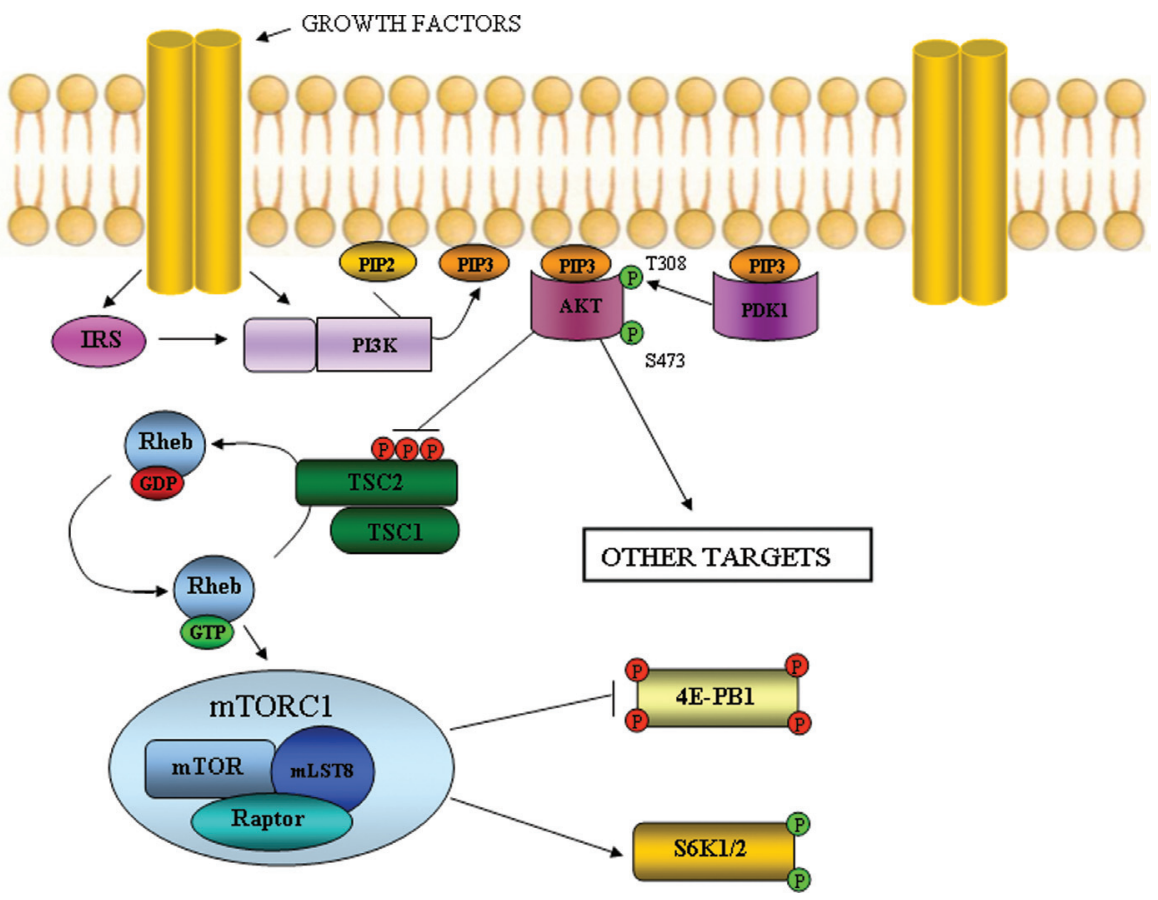

Figure 2 - The role of the TSC2:TSC1 complex in the mTOR pathway. PI3K is activated by growth factors through direct interaction with receptors or through interaction with scaffolding adaptors, such as the IRS proteins. These interactions recruit PI3K to its substrate PtdIns(4,5)P2 (PIP2), allowing generation of the lipid second messenger PtdIns(3,4,5)P3 (PIP3). Akt and PDK1 are recruited to the cell plasma membrane through association with PIP3. This allows Akt to be activated through phosphorylation on Thr308 by PDK1 and Ser473 by mTORC2 (not shown). Once active, Akt phosphorylates many downstream targets, including multiple sites on TSC2. Phosphorylation of TSC2 impairs the GTPase activity of the TSC2:TSC1 complex, allowing Rheb-GTP to accumulate. Rheb-GTP in excess activates high levels of mTORC1, which in turn phosphorylates and inhibits 4E-BP1 and activates S6K1 and $\mathrm{S} 6 \mathrm{~K} 2$. By this way, mTORC1 influences on cell growth, translation factors activation and cell nutrition. 
genes, the inactivation of both TSC1 or both TSC2 alleles is necessary for benign or malignant tumor formation. The first hit is an inherited germline mutation in TSC1 or TSC2, which can be detected in approximately $85 \%$ of patients with the clinical features of TSC, and the second hit is somatic. There are multiple possible mechanisms for somatic inactivation of the wild-type alleles of TSC1 and TSC2, including loss of heterozygosity, mutation and promoter methylation. It is possible that epigenetic silencing mediated by micro-RNAs also occurs. Moreover, binding of TSC1 to TSC2 appears to stabilize intracellular TSC2 levels since uncomplexed TSC2 is subject to ubiquitinmediated degradation (Chong-Kopera et al., 2006). Thus, $\mathrm{TSC} 1$ has a role in stabilizing the complex, while TSC2 has the GTPase activity. For this reason, inactivating mutations in either gene give rise to the same clinical disorder. Clearly, both proteins play pivotal roles in several processes that are crucial for normal brain development. In addition, because they are widely expressed throughout the mature brain, these proteins likely have important homeostatic regulatory functions in neurons during adult life.

Although several TSC families exhibit an autosomal dominant pattern of inheritance, $70 \%$ of the cases result from de novo germline mutations. Linkage studies initially suggested that there would be equivalent numbers of families with mutations in each TSC gene (Benvenuto et al., 2000). However, the frequency of mutations reported in TSC2 is consistently higher than in TSC1; TSC1 mutations account for only $10 \%$ to $30 \%$ of the families identified with TSC. In sporadic TSC, there is an even greater excess of mutations in TSC2. Nonetheless, identification of TSC1 mutations appears to be twice as likely in familial cases as in sporadic cases. The disparity in mutational frequency may reflect an increased rate of germline and somatic mutations in TSC2 as compared with TSC1, as well as an ascertainment bias, since mutations in $T S C 2$ are associated with more severe disease (Dabora et al., 2001; Jansen et al., 2008; Kothare et al., 2014). In patients with the TSC phenotype and no identifiable mutations in either TSCl or TSC2 (15\% to 20\%), the disease is usually milder (Dabora et al., 2001). A milder phenotype has also been described in rare individuals with mosaicism for mutations in $\mathrm{TSCl}$ or $T S C 2$. Caignec et al. (2009) reported a unique family with three independent pathogenic mutations in TSC2 mapping to distinct haplotypes. The three mutations were most likely de novo, as parents of the affected patients did not present any features of TSC. In addition, findings consistent with gonadal mosaicism were seen in one branch of the family.

\section{Molecular diagnosis in TSC}

The development of novel techniques and great advances in high-throughput genetic analysis in the last few years made mutation screening of the TSC1 and TSC2 genes feasible. Recent massively parallel sequencing technologies (Next-Generation Sequencing, NGS) and copy number variation testing (Multiplex Ligation-dependent Probe Amplification - MLPA and array-Comparative Genomic Hybridization - aCGH) have been validated for clinical use in many disorders including TSC, rendering the analysis much faster and more cost-effective.

Extensive studies of the TSC1 and TSC2 genes in patients with TSC have revealed a wide spectrum of mutations. We searched the PubMed database to retrieve available published literature in English from 1998 to 2014 that described mutations at TSC1 and TSC2 genes and established genotype-phenotype correlations for tuberous sclerosis disease. The following keywords were used: TSC1 mutations; TSC2 mutations; tuberous sclerosis complex; TSC mutations; TSC molecular analysis; genotypephenotype correlation on tuberous sclerosis. Twenty-seven studies were included in the final analysis. Table 2 summarizes the results obtained in the main studies performed with unrelated TSC patients worldwide; many of the changes listed were found for the first time in the investigated population. The most frequent mutation type is point mutations. Large gene rearrangements are less frequently reported, both because of their true prevalence in TSC and also because several studies did not use methodologies that are directed to the identification of such mutations. As expected, the observed mutation detection rate is not always complete. In this group, a mutation could exist in an intronic region distant from the exon-intron boundaries, which could have an effect on the splicing process or gene regulation, causing a reduction of normal mRNA transcript. Although a third gene for TSC may exist and explain this lack of mutation at TSC1 and TSC2 genes in some patients, there is currently no concrete evidence for this. Also, somatic and germ line mosaicism is a credible explanation for the failure to detect mutations in some patients, and specialized methods can be used to enhance detection of these specific situations. Most studies in TSC patients were conducted in Europe and Asia. The largest cohorts are from the Netherlands and Poland/USA. As expected through observed mutation frequencies, in all populations described, the germline mutation rate at the TSC2 locus was higher than that at the TSC1 locus. Also, the frequency of small rearrangements (small insertions/deletions) is higher than missense, nonsense and splice site mutations in all populations.

The exponential discovery rate of novel genomic alterations that cause TSC stimulated the creation and storage of genetic information in mutation databases. In the Human Genome Mutation Database (HGMD) for instance, 30 unique missense and 59 nonsense mutations in TSC1 had been described by 2014, as well as 91 small deletions, 41 small insertions, 31 splice site mutations and 21 large rearrangements. In this database, TSC1 mutations correspond to $93 \%$ of the mutations, with the largest number of these occurring in exon 15, which is the largest in basepairs (559). Proportionally, it corresponds to a mutation fre- 


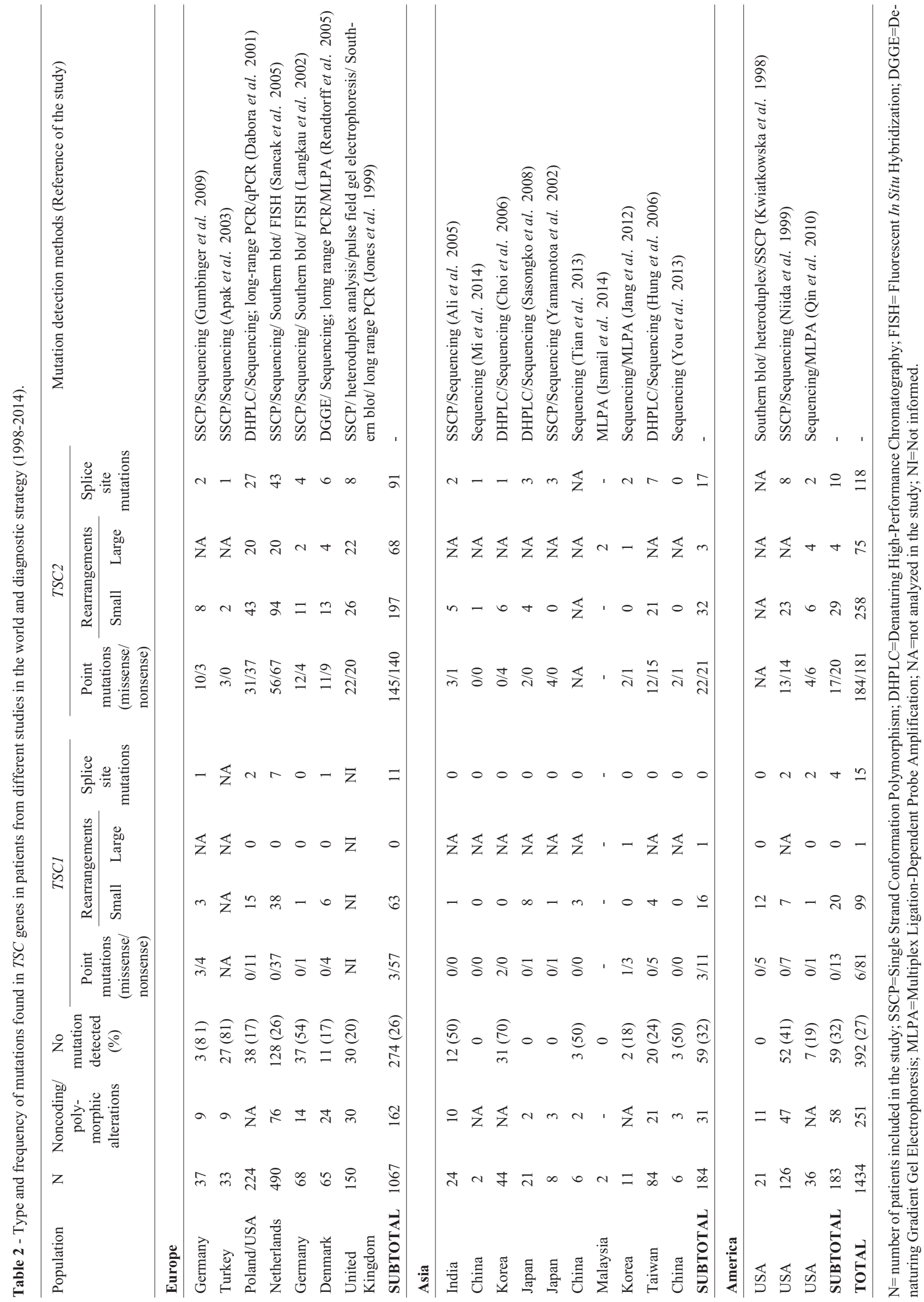


quency of $9.5 \%$ (determined as the percentage of mutations per base pairs, considering the size of each exon) and the highest mutation frequency is in exon 13 (14.3\%). Considering all exons, the average frequency of observed mutations is $5.9 \%$. Seven of the 23 exons have higher values (above $9 \%$ ). Small deletions are responsible for $41 \%$ of the disease and small insertions, for $18.5 \%$. Large rearrangements are responsible for 7\% of mutations in TSC1 at this database. The predicted coiled-coil domain of hamartin corresponds to exons $17-23$, where $21.9 \%$ of the mutations are localized. Exons 17-18 are responsible for interaction with tuberin, and they account for $15.9 \%$ of the point mutations described. Another database, the Leiden Open Variation Database (LOVD), reports 690 unique DNA variants for the $T S C 1$ gene.

Considering the TSC2 gene, 183 unique missense and 125 nonsense mutations gene are described in the HGMD database, as well as 189 small deletions, 99 small insertions, 120 splice site mutations and 148 large rearrangements. Point mutations correspond to $82.6 \%$ of the mutations, with the largest number of these occurring in exon 33, which is the largest in basepairs (488). Proportionally, this exon corresponds to a mutation frequency of $15.45 \%$, and the highest mutation frequency is in exon 37 $(22.9 \%)$ and exon 38 (22.8\%). Considering all exons, average frequency of observed mutations is $11.0 \%$, a higher number than mutation frequency at the TSC1 gene. Twenty-seven of the 41 exons have mutation frequency values above $9 \%$ and an overall mutation number and mutation frequency higher than that at the TSC1 gene. Small deletions are responsible for $32 \%$ of the disease versus $41 \%$ in the TSC1 gene, and small insertions for $17 \%$ versus $18.5 \%$ in the TSC1 gene. Large rearrangements are not shown in the table, and are responsible for $17.4 \%$ of mutations in $T S C 2$, a higher number than the frequency of large rearrangements in the TSCl gene.

The predicted coiled-coil domain of tuberin corresponds to exon 10 of the TSC2 gene, where only $1.8 \%$ of small mutations are localized. Exons 34-38 encode the GAP-domain, responsible for the essential GTPase activaty, and they account for $18.1 \%$ of the point mutations described at this gene, with a high mutation frequency (95.1\%). Exons 37 and 38 have shown the highest mutation frequency in the TSC2 gene, and these mutations can have a damage effect on the protein since the GAP domain can be disrupted. In the Leiden Open Variation Database, 1925 unique DNA variants on TSC2 gene have been reported.

Figure 1A illustrates the distribution of point mutations among all exons and domains of the TSC1 and TSC2 genes described in these different studies, and Figure 1B graphically represents the occurrence of point mutations in each of the TSC1 and TSC2 exons (percentage of the total number of described mutations in the HGMD database that occurs in each exon). This percentage is not related to exon size, but larger exons contain more mutations than smaller exons.

Because TSC can be a devastating disease, family members of affected individuals are often eager to know whether they are carriers of TSC mutations. Currently, with the adventure of next generation sequencing platforms, it became possible to analyze point mutations in both TSC1 and TSC2 genes at the same time for a lower cost; if no mutations are detected, the search for large deletions and duplications should proceed. Prenatal and preimplantation genetic tests are also becoming more widely available. The mutation status of family members has great implications on genetic counseling. Furthermore, for all clinical diagnostic criteria, patients with subclinical TSC may not be correctly diagnosed, and genetic testing is also very important for these cases.

The second International Tuberous Sclerosis Complex Consensus Conference brought together 79 experts from 14 countries to finalize diagnostic, surveillance, and management recommendations for patients with TSC (Northrup et al., 2013). At this meeting, the most significant change recommended was the incorporation of genetic testing in the diagnostic criteria. Molecular testing of the TSC1 and TSC2 genes yields a positive mutation result for $75-90 \%$ of TSC-affected individuals categorized as having definite Clinical Diagnostic Criteria. The recommendation of the Genetics Panel was to make the identification of a pathogenic mutation in TSC1 or TSC2 an independent diagnostic criterion, regardless of the clinical findings. This will facilitate the diagnosis of TSC in some, particularly young individuals, allowing earlier implementation of surveillance and treatment with a potential for better clinical outcomes. TSC1 and TSC2 genetic variants whose functional effect is not definitely pathogenic would not be considered a major diagnostic criterion. Finally, a normal result from TSC1 and TSC2 testing does not exclude TSC, since a fraction of TSC patients has no mutation identified by conventional genetic testing. Nonetheless, if the mutation in an affected relative is known, testing for that mutation has very high predictive value for family members.

\section{Genotype-phenotype correlations in TSC}

The discovery of the underlying genetic defects in TSC has furthered our understanding of this complex genetic disorder and genotype-phenotype correlations are becoming possible. In a retrospective study, Kothare et al. (2014) analysed a series of 919 TSC patients and found that carriage of a germline TSC2 mutation was associated with SENs and SGCTs. Occurrence of tubers, however, did not differ between carriers of TSC1 or TSC2 mutations. In general, patients with $T S C 2$ mutation presented with symptoms at a younger age. Dabora et al. (2001) analyzed 224 TSC patients and found that seizures, average cortical tuber number and SEN are more frequent or severe in patients with de novo TSC2 mutations than those with TSC1 muta- 
Table 3 - Genotype-phenotype correlations established for TSC patients.

\begin{tabular}{|c|c|c|c|c|c|c|}
\hline Population & $\mathrm{N}$ & Locus of DNA alteration & $\begin{array}{l}\text { Amino } \\
\text { acid change }\end{array}$ & Type of alteration & $\begin{array}{l}\text { Main associated } \\
\text { symptoms }\end{array}$ & Reference \\
\hline EUA & 1039 & TSC2 & - & Any type on $T S C 2$ & $\begin{array}{l}\text { Mutations in the } T S C 2 \\
\text { gene were more frequent } \\
\text { than } T S C 1 \text { gene in patients } \\
\text { with retinal findings }\end{array}$ & (Aronow et al., 2012) \\
\hline Poland & 170 & $\begin{array}{c}\text { TSC2 c.5238-5255del } \\
18 \mathrm{pb}\end{array}$ & - & Frameshift & Epilepsy & (Rok et al., 2005) \\
\hline USA & 220 & $\begin{array}{c}\text { Contiguous deletion } \\
\text { TSC2-PKD1 }\end{array}$ & - & $\begin{array}{l}\text { Large rearrange- } \\
\text { ment }\end{array}$ & $\begin{array}{l}\text { Arachnoid cysts and } \\
\text { polycystic kidney disease }\end{array}$ & (Boronat et al., 2014) \\
\hline Poland/USA & 224 & TSC2 & - & Any type on $T S C 2$ & $\begin{array}{l}\text { Seizures, mental retarda- } \\
\text { tion, average tuber count, } \\
\text { subependymal nodules, re- } \\
\text { nal angiomyolipomas, } \\
\text { angiofibromas and fibrous } \\
\text { forehead plaques were } \\
\text { more common and severe } \\
\text { in TSC2 patients }\end{array}$ & (Dabora et al., 2001) \\
\hline Netherlands & 490 & $T S C 1$ & - & Any type on $T S C 1$ & $\begin{array}{l}\text { Shagreen patches are more } \\
\text { frequent in patients with } \\
\text { TSC1 mutation }\end{array}$ & (Sancak et al., 2005) \\
\hline Netherlands & 490 & TSC2 & - & Any type on $T S C 2$ & $\begin{array}{l}\text { Mental retardation is more } \\
\text { frequent in patients with } \\
\text { TSC } 2 \text { mutation }\end{array}$ & (Sancak et al., 2005) \\
\hline Netherlands & 490 & $T S C 2$ & - & $\begin{array}{l}\text { Nonsense and } \\
\text { frameshift }\end{array}$ & $\begin{array}{l}\text { Shagreen patches, forehead } \\
\text { plaques, facial } \\
\text { angiofibromas, ungual } \\
\text { fibromas, renal } \\
\text { angiomyolipomas and renal } \\
\text { cysts }\end{array}$ & (Sancak et al., 2005) \\
\hline Netherlands & 490 & TSC2 & - & $\begin{array}{l}\text { Mutations in the } \\
\text { GAP domain }\end{array}$ & $\begin{array}{l}\text { Mental retardation, seizures } \\
\text { and subependymal nodules }\end{array}$ & (Sancak et al., 2005) \\
\hline Korea & 11 & TSC2 & - & $\begin{array}{c}\text { Mutations in exons } \\
\text { 33-41 }\end{array}$ & Cardiac rhabdomyomas & (Jang et al., 2012) \\
\hline USA & 65 & $T S C 2$ & - & Any type on $T S C 2$ & $\begin{array}{l}\text { Higher number of cysts } \\
\text { than } T S C 1 \text { woman with } \\
\text { pulmonary } \\
\text { lymphangioleiomyomatosis }\end{array}$ & (Muzykewicz et al., 2009) \\
\hline Canada & 19 families & TSC2 & R905Q & Missense & Milder disease severity & (Jansen et al., 2006) \\
\hline USA & 478 & $\begin{array}{l}T S C 2 \text { proximal region } \\
\text { (exons 1-22) and distal } \\
\text { region (exons 34-41) }\end{array}$ & - & $\begin{array}{l}\text { Missense muta- } \\
\text { tions and small } \\
\text { in-frame deletions } \\
\text { or insertions }\end{array}$ & $\begin{array}{l}\text { Proximal and distal TSC2 } \\
\text { mutations showed a signifi- } \\
\text { cantly higher risk of infan- } \\
\text { tile spasms compared with } \\
\text { mutations in the central re- } \\
\text { gion of the gene }\end{array}$ & (van Eeghena et al., 2013) \\
\hline $\begin{array}{l}\text { USA and } \\
\text { Belgium }\end{array}$ & 919 & TSC2 & - & Any type on $T S C 2$ & $\begin{array}{l}\text { More frequent occurrence } \\
\text { of several kinds of sei- } \\
\text { zures/epilepsy subtypes: } \\
\text { partial epilepsy, complex } \\
\text { partial seizures, infantile } \\
\text { spasms, SENs, SGCTs and } \\
\text { cognitive impairment. }\end{array}$ & (Kothare et al., 2014) \\
\hline $\begin{array}{l}\text { United } \\
\text { Kingdom }\end{array}$ & $\begin{array}{l}\text { One case } \\
\text { report }\end{array}$ & $\begin{array}{l}\text { TSC1 intron } 10 \\
\text { (c. } 1030-3 \mathrm{C}>\mathrm{G})\end{array}$ & - & $\begin{array}{l}\text { Splice site } \\
\text { mutation }\end{array}$ & $\begin{array}{l}\text { Mild phenotype (seizures } \\
\text { and small number of } \\
\text { hypomelanotic macules) }\end{array}$ & (Blyth et al., 2010) \\
\hline
\end{tabular}

$\mathrm{N}=$ number of patients included in the study.

$\mathrm{NI}=$ Not informed. 
tions. Jansen et al. (2008) also reported a more severe neurologic phenotype, including an earlier age of seizure onset, lower cognition index and more tubers in patients with a TSC2 mutation as compared to those with a TSC1 mutation. Another important correlation involves a subgroup of large genomic deletions at TSC2 that also affect the adjacent $P K D 1$ gene, causing early-onset polycystic kidney disease (Osborne et al., 1991).

Table 3 shows a compilation of the main genotypephenotype correlations described to date. As expected, most TSC2 mutations are generally associated with a more severe phenotype. Only one TSC2 mutation, R905Q, was associated with milder disease. This mutation was found in 25 individuals from the same family, with a phenotype characterized by the complete absence of disfiguring skin lesions, intractable epilepsy, mental retardation, and severe organ involvement. So, the type and location of mutations in both TSC1 and TSC2 genes also have an influence in the phenotype. Hamartin and tuberin are known to bind to at least 40 additional proteins, and thus there are numerous potential and yet undefined effects of TSC gene mutations. Futhermore, it is likely that other events such as mosaicism, the nature and frequency of the second event of inactivation of the second allele and the modifying genes, as well as environmental effects may interfere with the phenotype, which makes it more difficult to establish clear genotypephenotype correlations. Moreover, polymorphic and nonpathogenic variants in the TSC1 and TSC2 genes can act as phenotype modifiers in tuberous sclerosis, and they need to be further explored. To date, little is known about nonpathogenic variants in these genes, and phenotype modifiers in tuberous sclerosis have not been identified so far.

In light of emerging human genetic and molecular knowledge, molecular diagnosis of TSC and determination of genotyope-phenotype correlations might help in the establishment of personalized treatment for TSC patients and improve quality of life among these patients. Continuous studies in this area can guide future directions in this line.

\section{References}

Ali M, Girimaji SC, Markandaya M, Shukla AK, Sacchidanand S and Kumar A (2005) Mutation and polymorphism analysis of TSC1 and TSC2 genes in Indian patients with tuberous sclerosis complex. Acta Neurol Scand 111:54-63.

Apak A, Haliloolu G, Kose G, Yilmaz E, Anlar B and Aysun S (2003) Mutation analysis of TSC2 gene in 33 Turkish familial cases with tuberous sclerosis. Turk J Pediatr 45:1-5.

Aronow ME, Nakagawa JA, Gupta A, Traboulsi EI and Singh AD (2012) Tuberous sclerosis complex: Genotype/phenotype correlation of retinal findings. Ophthalmology 119:19171923.

Benvenuto G, Li S, Brown SJ, Braverman R, Vass WC, Cheadle JP, Halley DJ, Sampson JR, Wienecke R and DeClue JE (2000) The tuberous sclerosis-1 (TSC1) gene product hamartin suppresses cell growth and augments the expression of the TSC2 product tuberin by inhibiting its ubiquitination. Oncogene 19:6306-6316.

Blyth M, Raponi M, Treacy R, Raymond FL, Yates JR and Baralle D (2010) Expanding the tuberous sclerosis phenotype: Mild disease caused by a TSC1 splicing mutation. J Neurol Neurosurg Psychiatry 81:350-352.

Boronat S, Caruso P, Auladell M, Van Eeghen A and Thiele EA (2014) Arachnoid cysts in tuberous sclerosis complex. Brain Dev 36:801-806.

Caignec CL, Kwiatkowski DJ, Kury S, Hardouin JB, Melki J and David A (2009) Three independent mutations in the TSC2 gene in a family with tuberous sclerosis. Eur J Hum Genet 17:1165-1170.

Castro M, Sheperd CW, Gomez MR and Lie JT (1995) Pulmonary tuberous sclerosis. Chest 107:189-195.

Choi JE, Chae JH, Hwang YS and Kim KJ (2006) Mutational analysis of TSC1 and TSC2 in Korean patients with tuberous sclerosis complex. Brain Dev 28:440-446.

Chong-Kopera H, Inoki K, Li Y, Zhu T, Garcia-Gonzalo FR, Rosa JL and Guan KL (2006) TSC1 stabilizes TSC2 by inhibiting the interaction between TSC 2 and the HERC1 ubiquitin ligase. J Biol Chem 281:8313-8316.

Cuccia V, Zuccaro G, Sosa F, Monges J, Lubienieky F and Taratuto AL (2003) Subependymal giant cell tumor in children with tuberous sclerosis. Childs Nerv Syst 19:232-243.

Dabora SL, Jozwiak S, Franz DN, Roberts PS, Nieto A, Chung J, Choy YS, Reeve MP, Thiele E, Egelhoff JC, et al. (2001) Mutational analysis in a cohort of 224 tuberous sclerosis patients indicates increased severity of TSC2, compared with TSC1 disease in multiple organs. Am J Hum Genet 68:6480.

Dixon BP, Hulbert JC and Bissler JJ (2011) Tuberous sclerosis complex renal disease. Nephron Exp Nephrol 118:15-20.

Frèrebeau P, Benezech J, Segnarbieux F, Harbi H, Desy A and Marty-Double CH (1985) Intraventricular tumors in tuberous sclerosis. Childs Nerv Syst 1:45-48.

Gumbinger C, Rohsbach CB, Schulze-Bonhage A, Korinthenberg R, Zentner J, Häffner M and Fauser S (2009) Focal cortical dysplasia: A genotype-phenotype analysis of polymorphisms and mutations in the TSC genes. Epilepsia 50:13961408.

Hung CC, Su YN, Chien SC, Liou HH, Chen CC, Chen PC, Hsieh CJ, Chen CP, Lee WT, Lin WL, et al. (2006) Molecular and clinical analyses of 84 patients with tuberous sclerosis complex. BMC Med Genet 7:e72.

Ismail NFD, Malik NMANA, Mohseni J, Rani AM, Hayati F, Salmi AR, Narazah MY, Zabidi-Hussin ZA, Silawati AR, Keng WT, et al. (2014) Two novel gross deletions of TSC2 in Malaysian patients with Tuberous Sclerosis Complex and TSC2/PKD1 Contiguous Deletion Syndrome. Jpn J Clin Oncol 44:506-511.

Jang MA, Hong SB, Lee JH, Lee MH, Chung MP, Shin HJ, Kim JW and Ki CS (2012) Identification of TSC1 and TSC2 mutations in Korean patients with Tuberous Sclerosis Complex. Pediatr Neurol 46:222-224.

Jansen AC, Sancak O, D'Agostino MD, Badhwar A, Roberts P, Gobbi G, Wilkinson R, Melanson D, Tampieri D and Koenekoop R (2006) Unusually mild tuberous sclerosis phenotype is associated with TSC2 R905Q mutation. Ann Neurol 60:528-539. 
Jansen FE, Braams O, Vincken KL, Algra A, Anbeek P, Jennekens-Schinkel A, Halley D, Zonnenberg BA, van den Ouweland A, van Huffelen AC, et al. (2008) Overlapping neurologic and cognitive phenotypes in patients with TSC1 or TSC2 mutations. Neurology 70:908-915.

Joinson C, O'Callaghan FJ, Osborne JP, Martyn C, Harris T and Bolton PF (2003) Learning disability and epilepsy in an epidemiological sample of individuals with tuberous sclerosis complex. Psychol Med 33:335-344.

Jones AC, Shyamsundar MM, Thomas MW, Maynard J, Idziaszczyk S, Tomkins S, Sampson JR and Cheadle JP (1999) Comprehensive mutation analysis of TSC1 and TSC2 - and phenotypic correlations in 150 families with tuberous sclerosis. Am J Hum Genet 64:1305-1315.

Jozwiak S, Schwartz RA, Janniger CK, Michalowicz R and Chmielik J (1998) Skin lesions in children with tuberous sclerosis complex: Their prevalence, natural course, and diagnostic significance. Int J Dermatol 37:911-917.

Knudson AG (1971) Mutation and cancer: Statistical study of retinoblastoma. Proc Natl Acad Sci U S A 68:820-823.

Kothare SV, Singh K, Chalifoux JR, Staley BA, Weiner HL, Menzer K and Devinsky O (2014) Severity of manifestations in tuberous sclerosis complex in relation to genotype. Epilepsia 55:1025-1029.

Kumasaka T, Seyama K, Mitani K, Sato T, Souma S, Kondo T, Hayashi S, Minami M, Uekusa T, Fukuchi Y, et al. (2004) Lymphangiogenesis in lymphangioleiomyomatosis: Its implication in the progression of lymphangioleiomyomatosis. Am J Surg Pathol 28:1007-1016.

Kwiatkowska J, Jozwiak S, Hall F, Henske EP, Haines JL, McNamara P, Braiser J, Wigowska-Sowinska J, Kasprzyk-Obara J, Short MP, et al. (1998) Comprehensive mutational analysis of the TSC1 gene: Observations on frequency of mutation, associated features, and nonpenetrance. Ann Hum Genet 62:277-285.

Kwiatkowski DJ (2003) Rhebbing up mTor: New insights on $\mathrm{TSC} 1$ and TSC2, and the pathogenesis of tuberous sclerosis. Cancer Biol Ther 2:471-476.

Langkau N, Martin N, Brandt R, Zügge K, Quast S, Wiegele G, Jauch A, Rehm M, Kuhl A, Mack-Vetter M, et al. (2002) TSC1 and TSC2 mutations in tuberous sclerosis, the associated phenotypes and a model to explain observed TSC1/TSC2 frequency ratios. Eur J Pediatr 161:393-402.

Maheshwar M, Cheadle JP, Jones AC, Myring J, Fryer AE, Harris PC and Sampson JR (1997) The GAP-related domain of tuberin, the product of the TSC2 gene, is a target for missense mutations in tuberous sclerosis. Hum Mol Genet 6:1991-1996.

Mi CR, Wang H, Jiang H, Sun RP and Wang GX (2014) Mutation screening of TSC1 and TSC2 genes in Chinese Han children with tuberous sclerosis complex. Genet Mol Res 13:21022106.

Muzykewicz DA, Sharma A, Muse V, Numis AL, Rajagopal J and Thiele EA (2009) TSC1 and TSC2 mutations in patients with lymphangioleiomyomatosis and tuberous sclerosis complex. J Med Genet 46:465-468.

Niida Y, Lawrence-Smith N, Banwell A, Hammer E, Lewis J, Beauchamp RL, Sims K, Ramesh V and Ozelius L (1999) Analysis of both TSC1 and TSC2 for germline mutations in 126 unrelated patients with tuberous sclerosis. Hum Mutat 14:412-422.
Northrup H, Wheless JW, Bertin TK and Lewis RA (1993) Variability of expression in tuberous sclerosis. J Med Genet 30:41-43.

Northrup H, Krueger DA and International Tuberous Sclerosis Complex Consensus Group (2013) Tuberous sclerosis complex diagnostic criteria update: Recommendations of the 2012 International Tuberous Sclerosis Complex Consensus Conference. Pediatr Neurol 49:243-254.

O'Callaghan F and Osborne J (2010) Endocrine, gastrointestinal, hepatic, and lymphatic manifestations of tuberous sclerosis complex. In: Kwiatkowski D, Whittemore V and Thiele E (eds) Tuberous Sclerosis Complex: Genes, Clinical Features, and Therapeutics. Wiley-Blackwell, Weinheim, pp 369-385.

Osborne JP, Fryer A and Webb D (1991) Epidemiology of tuberous sclerosis. Ann NY Acad Sci 615:25-127.

Qin W, Chan JA, Vinters HV, Mathern GW, Franz DN, Taillon BE, Bouffard P and Kwiatkowski DJ (2010) Analysis of TSC cortical tubers by deep sequencing of TSC1, TSC2 and $K R A S$ demonstrates that small second-hit mutations in these genes are rare events. Brain Pathol 20:1096-1105.

Rendtorff ND, Bjerregaard B, Frodin M, Kjaergaard S, Hove H, Skovby F, Brøndum-Nielsen K, Schwartz M and Danish Tuberous Sclerosis Group (2005) Analysis of 65 Tuberous Sclerosis complex (TSC) patients by TSC2 DGGE, TSC1/TSC2 MLPA, and TSC1 Long-Range PCR Sequencing, and report of 28 novel mutations. Hum Mutat 26:374383.

Roach ES, Gomez MR and Northrup H (1998) Tuberous sclerosis complex consensus conference: Revised clinical diagnostic criteria. J Child Neurol 13:624-628.

Robertson DM (1999) Ophthalmic findings. In: Gomez MR, Sampson JR and Whittemore VH (eds) Tuberous Sclerosis Complex. $3^{\text {rd }}$ ed. Oxford University Press, New York, pp 145-159.

Rok P, Kasprzyk-Obara J, Domanska-Pakiela D and Józwiak S (2005) Clinical symptoms of tuberous sclerosis complex in patients with an identical TSC2 mutation. Med Sci Monit 11:230-234.

Rowley SA, O'Callaghan FJO and Osborne JP (2001) Ophthalmic manifestations of tuberous sclerosis: A population based study. Br J Ophthalmol 85:420-423.

Sampson JR, Maheshwar MM, Aspinwall R, Thompson P, Cheadle JP, Ravine D, Roy S, Haan E, Bernstein J and Harris PC (1997) Renal cystic disease in tuberous sclerosis: Role of the polycystic kidney disease 1 gene. Am J Hum Genet 61:843851.

Sancak O, Nellist M, Goedbloed M, Elfferich P, Wouters C, Maat-Kievit A, Zonnenberg B, Verhoef S, Halley D and van den Ouweland A (2005) Mutational analysis of the TSC1 and TSC2 genes in a diagnostic setting: Genotype-phenotype correlations and comparison of diagnostic DNA techniques in Tuberous Sclerosis Complex. Eur J Hum Genet 13:731-741.

Sasongko TH, Wataya-Kaneda M, Koterazawa K, Gunadi, Yusoff S, Harahap IS, Lee MJ, Matsuo M and Nishio H (2008) Novel mutations in 21 patients with tuberous sclerosis complex and variation of tandem splice-acceptor sites in TSC1 exon 14. Kobe J Med Sci 54:73-81. 
Schwartz RA, Fernandez G, Kotulska K and Jozwiak S (2007) Tuberous sclerosis complex: Advances in diagnosis, genetics, and management. J Am Acad Dermatol 57:189-202.

Serfontein J, Nisbet R, Howe CJ and de Vries PJ (2011) Conservation of structural and functional elements of TSC1 and TSC2: A bioinformatic comparison across animal models. Behav Genet 41:349-356.

Shepherd CW, Gomez MR, Lie JT and Crowson CS (1991) Causes of death in patients with tuberous sclerosis. Mayo Clin Proc 66:792-796.

Sun XF, Yan CL, Fang L, Shen FM and Liao KH (2005) Cutaneous lesions and visceral involvement of tuberous sclerosis. Chin Med J (Engl) 118:215-219.

Tian H, Wang X, Wu M, Zhou G and Lu X (2013) Three novel mutations of TSC1 gene in Chinese patients with tuberous sclerosis complex. Int J Dermatol 52:1274-1290.

van Eeghena AM, Nellist M, van Eeghena EE and Thiele EA (2013) Central TSC2 missense mutations are associated with a reduced risk of infantile spasms. Epilepsy Res 103:83-87.

Webb DW, Fryer AE and Osborne JP (1996) Morbidity associated with tuberous sclerosis: A population study. Dev Med Child Neurol 38:146-155.

Yamamotoa T, Pipob JR, Fengb JH, Takeda H, Nanba E, Ninomiya H and Ohno K (2002) Novel TSC1 and TSC2 mutations in Japanese patients with tuberous sclerosis complex. Brain Dev 24:227-230.
Yates JR (2006) Tuberous sclerosis. Eur J Hum Genet 14:10651073.

You J, Liu H, Fu X, Chen M, Niu G, Tian H and Zhang F (2013) Two novel TSC2 mutations in Chinese patients with tuberous sclerosis complex. Indian J Dermatol Venereol Leprol 79:104-105.

\section{Internet resources}

HGMD - Human Genome Mutation Database, http://www.hgmd.cf.ac.uk/ac/index.php (accessed in November, 2014).

LOVD - Leiden Open Variation Database (http://www.lovd.nl/3.0/home), access in November, 2014.

Orphanet: Tuberous Sclerosis, http://www.orpha.net/consor/cgi-bin/Disease_Search.php?lng $=$ EN\&data_id $=660 \&$ MISSING $\% 20 \mathrm{C}$ ONTENT $=$ Tuberous-sclerosis\&search $=$ Disease_Search_Simple\&title=Tuberous-sclerosis (accessed in May, 2015).

Associate Editor: Carlos F. M. Menck

License information: This is an open-access article distributed under the terms of the Creative Commons Attribution License (type CC-BY), which permits unrestricted use, distribution and reproduction in any medium, provided the original article is properly cited. 